Review Article

\title{
Recent Trends in Nanocarrier-Based Targeted Chemotherapy: Selective Delivery of Anticancer Drugs for Effective Lung, Colon, Cervical, and Breast Cancer Treatment
}

\author{
Ke-Tao Jin $\mathbb{D}^{1},{ }^{1}$ Ze-Bei Lu, ${ }^{2,3,4}$ Jin-Yang Chen, ${ }^{5}$ Yu-Yao Liu, ${ }^{1}$ Huan-Rong Lan, ${ }^{6}$ \\ Hai-Ying Dong, ${ }^{3}$ Fan Yang $\left(1,{ }^{2}\right.$ Yuan-Yuan Zhao, ${ }^{7}$ and Xiao-Yi Chen $\mathbb{1}^{3,4}$ \\ ${ }^{1}$ Department of Colorectal Surgery, Shaoxing People's Hospital (Shaoxing Hospital, Zhejiang University School of Medicine), \\ Shaoxing, 312000 Zhejiang Province, China \\ ${ }^{2}$ Department of Stomatology, Zhejiang Provincial People's Hospital (People's Hospital of Hangzhou Medical College), Hangzhou, \\ 310014 Zhejiang Province, China \\ ${ }^{3}$ Key Laboratory of Tumor Molecular Diagnosis and Individualized Medicine of Zhejiang Province, Zhejiang Provincial People's \\ Hospital (People's Hospital of Hangzhou Medical College), Hangzhou 310014, China \\ ${ }^{4}$ Clinical Research Institute, Zhejiang Provincial People's Hospital (People's Hospital of Hangzhou Medical College), \\ Hangzhou 310014, China \\ ${ }^{5}$ Research and Development Department, Zhejiang Health Future Institute for Cell-Based Applied Technology, Hangzhou, \\ 310052 Zhejiang Province, China \\ ${ }^{6}$ Department of Breast and Thyroid Surgery, Shaoxing People's Hospital (Shaoxing Hospital, Zhejiang University School of Medicine), \\ Shaoxing, 312000 Zhejiang Province, China \\ ${ }^{7}$ Department of Neurosurgery, Zhejiang Provincial People's Hospital (People's Hospital of Hangzhou Medical College), Hangzhou, \\ 310014 Zhejiang Province, China
}

Correspondence should be addressed to Fan Yang; yangfan@hmc.edu.cn and Xiao-Yi Chen; chenxiaoyi@hmc.edu.cn

Received 18 March 2020; Revised 23 May 2020; Accepted 10 June 2020; Published 2 July 2020

Guest Editor: Anuj Kumar

Copyright (c) $2020 \mathrm{Ke}$-Tao Jin et al. This is an open access article distributed under the Creative Commons Attribution License, which permits unrestricted use, distribution, and reproduction in any medium, provided the original work is properly cited.

\begin{abstract}
Chemotherapy drugs are cytotoxic to tumor cells, but their lack of specificity leads to a range of side effects. The off-target effects of such drugs can be improved through the use of nanoparticles (NPs). Administered NPs show enhanced accumulation in tumor tissue near the blood vessels, enhancing both anticancer drug permeability and tumor retention. Several nanocarriers are now approved for clinical use in a range of cancer therapies, and many novel formulations are in the later stages of clinical trials. Here, we describe the advances in this area through the review of novel NP drug formulations developed over the last year. We focus specifically on lung, colon, cervical, and breast cancers and discuss the future of NPs as potential treatment options in these areas.
\end{abstract}

\section{Introduction}

Cancer encompasses a variety of diseases that result from the deregulated growth and spread of malignant cells. According to recent World Health Organization (WHO) statistics, up to 10 million new cancer cases are estimated to occur each year and are projected to increase to 13 million cases in the next 20 years [1]. Despite the increased occurrence, cancerrelated mortality has decreased due to improved diagnostics, molecular knowledge of cancer cell biology, and treatments [2]. Cancer therapy typically involves surgery, chemotherapy, and radiation therapy alone or in combination, with sequencing technologies, permitting the era of precision therapy that tailors cancer treatments to the genetic basis of each individual cancer $[3,4]$. Chemotherapy drugs primarily interfere with DNA synthesis, targeting rapidly dividing cancer cells. These agents, whilst effective, are nonspecific, leading to healthy tissue damage and subsequent side effects that 
can contribute to the high mortality rates of cancer patients [5]. An additional issue with chemotherapy drugs is the increased incidence of drug resistance [6]. Hence, the ability to develop chemotherapeutics that actively target cancer cells is highly desirable.

In recent years, the improved understanding of tumor biology combined with the advancements in the development of versatile materials has led to improved drug delivery systems of chemotherapeutics to tumor sites. More specifically, nanotechnology has profoundly improved clinical cancer therapeutics in the last 20 years [7-12]. NP-based drug delivery systems or nanocarriers can improve drug efficacy and selectivity through enhanced permeability and retention (EPR) effects in tumor tissues [13-20]. Nanocarriers also display improved cellular uptake in comparison to standard chemotherapy drugs. Among the nanocarriers, liposomes, polymeric nanoparticles, and micelles have received the most attention [21]. To date, several nanoparticle-based chemotherapeutics are clinically approved whilst others are in the advanced stages of clinical development. However, nanocarriers are associated with certain drawbacks such as poor biodegradation, bioavailability, stability, tissue distribution, and toxicity, thus causing safety concerns, particularly for longterm cancer treatment. Herein, we will discuss drug delivery nanocarriers for cancer therapy to improve chemotherapeutics that have been developed recently. We will further discuss the future directions of NP-based cancer chemotherapy with a focus on lung, colon, and female cancers.

\section{Nanocarriers}

The physical and chemical properties of NPs greatly influence their efficacy. Nanoscale compounds from synthetic polymers, lipids, proteins, and inorganic particles have been developed [21-29]. They promote drug protection, solubility, and stability, enhancing drug delivery. NP functionalization with target specific ligands, such as folic acid, aptamers, peptides, and antibodies, permits the targeted delivery of drugs. The culmination of these benefits is numerous drug delivery vehicles with reduced toxic side effects and improved pharmacokinetics, which vary according to surface physicochemical properties and size [30-35].

Among organic nanocarriers, liposomes are spherical lipid vesicles composed of a self-forming phospholipid bilayer that surrounds an aqueous internal cavity $[25,36]$. The commercially available lipids for liposome NPs include cholesterol, phosphatidylcholine, phosphatidylethanolamine, and phosphatidylserine. Liposomes are attractive as they lack toxicity and easily internalize into tumor cells, permitting drug transport across cellular membranes. However, their major disadvantages are expensive preparation methods, low drug-loading capacity and stability, and rapid disintegration in the human body before achieving the therapeutic effect. ThermoDox ${ }^{\circledR}$, a thermosensitive liposomal formulation (TSL) containing doxorubicin, is the only TSL in development. This formulation selectively unloads its payload in the tumor microenvironment due to its responsiveness to a temperature above $40^{\circ} \mathrm{C}$, thus resulting in increased anticancer efficacy of its loaded drug [37]. The use of lipid-based nanocarriers as opposed to liquid oils permits controlled drug release through reducing drug mobility [38]. Solid lipid NPs (SLNs) are frequently used as NPs for intravascular administration and consist of a hydrophobic lipid core into which drugs can be dissolved permitting high drug-loading efficiencies [39]. Polymeric micelles are another form of lipid based-NP $<100 \mathrm{~nm}$ in size and composed of phospholipids and polymers that spontaneously form in aqueous solution $[40,41]$. They are suitable carriers for drugs with poor water solubility due to their amphiphilic characteristics, viz., hydrophobic core and hydrophilic shell. Reverse micelles (RMs) are frequently used due to their ease of solubility in oil phases [42-44]. However, a disadvantage of RMs is their lack of tissue specificity and inability to mediate targeted drug delivery [42]. Micellar nanocomplex (MNC) NPs are mainly composed of (-)-epigallocatechin-3-O-gallate (EGCG), an anti-inflammatory polyphenol [45]. MNCs can shield protein drugs from the action of proteolytic enzymes during transportation to the tumor tissues. Genexol-PM ${ }^{\circledR}$ is amphiphilic polymer-based micellar formulation loaded with paclitaxel and is used for the effective treatment of metastatic breast and small-lung-cell carcinoma. The formulation achieves enhanced anticancer activity of the drug to its long circulation as it gets avoidance body clearance [46].

Among nonlipid-based NPs, mesoporous materials hold promise due to their facile synthesis, highly ordered structures, biocompatibility, and large pore sizes, typically prepared from assemblies of inorganic components such as silica [30]. The pore size of mesoporous silica NPs (MSNs) influences their pharmacological potential in terms of drug adsorption, loading capacity, and drug release [30]. Pore diameters vary from 2 to $50 \mathrm{~nm}$ enabling the production of NPs that bind to small drug molecules or macromolecules. The stability of the pore also dictates controlled drugrelease kinetics. So far, MSNs characterized by temperature, $\mathrm{pH}$, irradiation, enzymes, magnetic field, ultrasound, and redox-based stimuli-responsive drug release have been developed [47].

Metal-organic frameworks (MOFs) constitute a class of porous NPs with differing hybrid structures that consist of a metal ion and an organic linker or spacer [48]. MOFs show promise for controlled drug release due to their large surface area and tunable pore size. However, MOFs must be scaled down to the nanoscale level for utility as in vivo anticancer drug carriers $[49,50]$. Nano-MOFs have particular utility in pharmaceutical applications as they permit controlled drug release $[49,50]$. Compared to conventional porous materials, nano-MOFs incorporate much higher amounts of drugs offering obvious advantages to cancer treatment. MOFbased stimuli-responsive systems responding to $\mathrm{pH}$, redoxbased, ATP, magnetic fields, temperature, pressure, irradiation, and humidity have been developed.

Recently, NPs based on biocompatible and biodegradable polymers such as polylactic acid (PLA) esters and their copolymers with glycolic acid (PLGA), poly( $\varepsilon$-caprolactone), polyglutamic acid, and poly(alkyl cyanoacrylate) have gained popularity for nanocarrier fabrication [51]. These polymers are broken down in the body to oligomers and monomers 
which are further eliminated via metabolic pathways. To surmount the issue of phagocytosis upon intravenous administration, the NPs may be coated with a hydrophilic polymer such as polyethylene glycol (PEG), which hinders the identification of the NPs by the reticuloendothelial system. Dendrimers, inorganic NPs, nanoemulsions, carbon-based nanomaterials, etc. are some of the other popular nanocarriers (Figure 1).

The first nanobased therapeutic approved by the FDA was the liposomal NP doxorubicin Doxil ${ }^{\circledR}$, a chemotherapeutic primarily employed for breast cancer $(\mathrm{BCa})$, bladder cancer, and acute lymphocytic leukemia treatment. This liposomal formulation results in enhanced anticancer activity of the drug due to long circulating properties of the liposomes achieved through inclusion of polyethylene glycol in their composition [52-56]. The development of this NP system was followed by Abraxane ${ }^{\circledR}$ (nab-paclitaxel), a BCa chemotherapy drug. Abraxane ${ }^{\circledR}$ is based on albumin NPs; albumin NPs not only increase the drug solubility but also localize the drug into tumors due to its higher affinity for hydrophobic molecules [57-61]. Notable nanocarriers that have undergone FDA approval or are in clinical trials are presented in Table 1 [54, 62-67]. Even though most of the FDA-approved nanocarriers rely on passive targeting via EPR, a few next-generation nanocarriers in clinical trials utilize active targeting approaches due to the recent advances in protein engineering and polymer chemistry.

\section{Recent Advances in Nanocarrier Delivery Systems for Cancer Treatment}

3.1. Anticancer Drug Targeted Delivery through NPs. Improved chemotherapy requires the drugs to cross the biological barriers followed by their selective localization in the target tumor tissues, thus leading to enhanced anticancer activity with minimum off-target side effects. Passive and active NP drug targeting is a widely used approach [86, 87]. In passive targeting, nanocarriers localize their loaded anticancer drugs passively in tumor tissues exploiting the physiopathologic characteristics of tumors such as tumor vasculature. Tumor vessel architecture becomes highly defective along with poor lymphatic drainage, thus leading to enhanced permeation and retention (EPR) effect $[88,89]$. Small size of nanocarriers and defective tumor vasculature are also exploited for anticancer drug passive targeting [90]. Blood vessels in the tumor tissue microenvironment have larger gaps $(100 \mathrm{~nm}-2 \mu \mathrm{m})$ in the endothelium; thus, they differ from that of the normal. Therefore, nanocarriers in this size range can easily reach tumors, resulting in selective localization of the drugs in tumors [91, 92]. Furthermore, tumor tissues are associated with poor lymphatic system which results in higher interstitial pressure at their centers than peripheries. This in turn leads to nanocarrier access into the interstitial space; thus, nanocarriers remain in interstitia for longer time with ultimate enhanced anticancer activity in tumors [93]. Passive targeting strategies through nanocarriers are depicted in Figure 2. Anticancer drugs can also be passively targeted through making nanocarriers long circulating. Such nanocarriers avoid clearance from the body and remain in biological systems for a longer time; thus, they pass through the tumor microenvironment repeatedly with ultimate increased anticancer activity of their loaded drugs. Similarly, cationic nanocarriers are also used to localize their loaded drugs in tumors due to their electrostatic interactions with angiogenic endothelial cells in tumor blood vessels $[86,87]$.

Active drug targeting uses nanocarrier surface modified with a targeting moiety. Targeting moiety attached to the surface of nanocarriers recognizes specific receptors or antigens associated with tumors as shown in Figure 3. This results in the selective localization of drugs in the site of action whilst preventing their uptake in healthy cells and tissues. Furthermore, some targeting ligands can trigger drug release from nanocarriers inside target cells via receptor-mediated endocytosis process [94]. Drug tumor internalization through receptor targeting is an effective approach for improved chemotherapy [95]. Cancer cells overexpress certain types of receptors; thus, targeting moieties recognize these receptors and highly selective drug localization in tumors is achieved $[96,97]$. Similarly, nanocarriers are also made responsive to the changes in the tumor microenvironment; drugs get released from nanocarriers in the tumor vicinity as a result of their responsiveness to those stimuli such as $\mathrm{pH}$, hyperthermia, redox potential, and certain enzymes in the tumor microenvironment $[86,87]$. Thus, increased drug concentration is achieved in the tumor microenvironment with ultimate improved chemotherapy.

3.1.1. Targeting Lung Cancer. Lung cancer (LCa) is a leading global cause of cancer-related deaths [98]. A chemotherapy regimen, dependent on it being either adenocarcinoma or squamous cell carcinoma, is often administered, combining 2 or 3 chemotherapy agents including cisplatin, docetaxel, gemcitabine, Abraxane ${ }^{\circledR}$, paclitaxel, pemetrexed, and vinorelbine $[98,99]$. Many promising NP formulations for LCa therapy have been described recently.

Due to their ability to permeate blood vessels and tissues into tumors, metal-based NPs can be applied as drug carriers for reducing cytotoxicity to healthy cells. Using nonorganicbased approaches, Ramalingam and coworkers conjugated Dox onto gold NPs using polyvinylpyrrolidone [100]. The NPs inhibited the proliferation of A549 cells, increased cellular ROS production, and led to the induction of apoptosis. Similarly, Kalaiarasi and colleagues synthesized copper oxide NPs that could downregulate specific oncogenes including histone deacetylase in A549 cells, leading to apoptotic induction [101]. Although platinum-based antitumor agents have been widely used for LCa, their clinical outcomes are largely limited by severe side effects and multidrug resistance. Hence, platinum(II)-loaded drug nanocarriers have been developed to overcome these drawbacks. For instance, Tsai and coworkers synthesized diaminocyclohexane-platinum(II)- (DACHPt-) loaded NPs through self-assembly that could be efficiently internalized by platinum- (Pt-) resistant LCa cell lines, inducing high levels of tumor toxicity [6]. Therefore, these DACHPt-loaded NPs provide a novel potent nanocarrier platform for combating multidrugresistant LCa. 


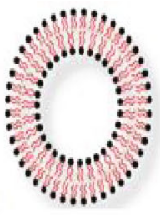

Liposomes

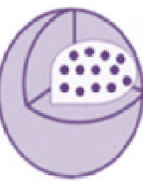

Polymeric nanoparticles

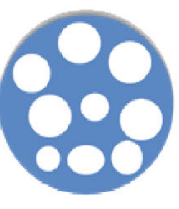

Mesoporous silica nanoparticles

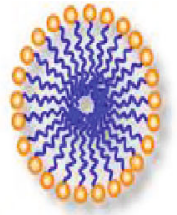

Micelles

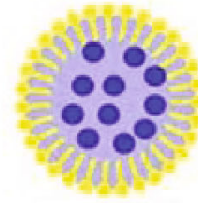

Solid lipid nanoparticles

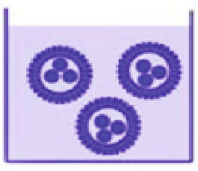

Nanoemulsions

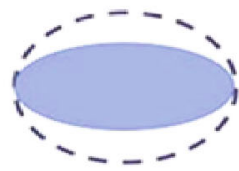

Self-emulsifying systems

(a) Lipid-based nanocarriers

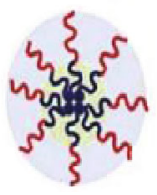

Polymeric micelles

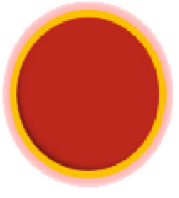

Gold nanoparticles

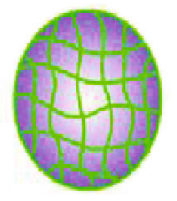

Polymeric hydrogels

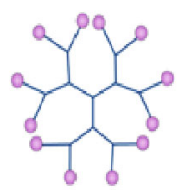

Dendrimers

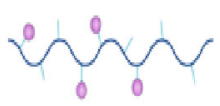

Polymer-drug

(b) Polymeric nanocarriers
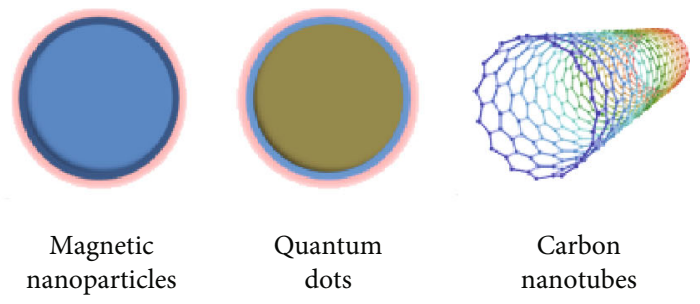

(c) Inorganic nanocarriers

FIgURE 1: Different types of nanocarriers for drug delivery in cancer therapy.

Active targeting can be achieved by coupling drugs or nanocarriers with cell-specific targeting moieties such as ligands, peptides, antibodies, and aptamers, which can distinguish between normal and tumor cells. For instance, Song and colleagues designed epidermal growth factor- (EGF-) conjugated core-shell lipid-polymer hybrid NPs (LPNs) to actively deliver docetaxel (DTX) and resveratrol (RSV) to tumor cells [36]. The biodegradable EGF-DTX/RSV-NPs showed synergistic tumor inhibition with minimal offtarget effects, highlighting their promise for LCa treatment. Nanocarriers based on vitamin E succinate display biocompatibility, hydrophobicity, ease of synthesis, and anticancer activity. On the other hand, hyaluronic acid (HA), a biocompatible and biodegradable anionic polysaccharide, permits active targeting of tumor cell CD44 receptors. To enhance tumor cell targeting and specific drug release, Song and coworkers synthesized redox-sensitive NPs from hyaluronic acid- (HA-) disulfide-vitamin E succinate conjugates that were loaded with paclitaxel (PTX) [12]. The PTX-loaded redox-sensitive NPs showed greater cytotoxicity in A549 cells and A549 mouse xenograft models compared to redoxinsensitive NPs and PTX alone, indicating their potential for PTX-targeted delivery for LCa treatment.

The clinical application of naringenin (NAR), a flavonoid, is limited by its low aqueous solubility, bioavailability, and stability. These drawbacks could be overcome by designing polymeric nanoparticles based on biocompatible and biodegradable polymers. Parashar et al. [102] designed chitosan- and HA-decorated naringenin poly caprolactone
NPs (NAR-HA@CS-PCL-NPs) that were cytotoxic to A549 cells but had no effect on noncancer cell lines. In vivo, the chemopreventive effects of the NAR-HA@CH-PCL-NPs were shown in urethane-induced LCa rat models. AS1411 is a 26base G-rich DNA oligonucleotide that functions as a nucleolin-binding aptamer overexpressed in a range of cancer cells [103]. Guo et al. [5] developed a multifunctional nanocarrier consisting of methotrexate-loaded fluorescent gold nanocluster-conjugated chitosan and AS1411 aptamers (MTX@AuNCs-CS-AS1411), which exhibited significant anticancer activity in A549 cells and inhibited tumor growth in $\mathrm{BALB} / \mathrm{c}$ mice. The codelivery of functionally distinct anticancer drugs is an efficient strategy to overcome drug resistance during LCa treatment. To achieve this, Amreddy et al. [104] synthesized folic acid-conjugated polyamidoamine (PAMAM) dendrimers to codeliver human antigen $\mathrm{R}(\mathrm{HuR})$ siRNA and cis-diamine platinum to folate receptor-alpha overexpressing LCa cells. The dendrimers produced greater therapeutic effects than the individual therapies alone whilst being nontoxic towards normal lung fibroblasts, which was attributed to the elevated HuR in LCa cells.

miRNA-29b inhibits DNA methylation in LCa cells by targeting DNA methyltransferases, further resulting in inhibition of cell proliferation and apoptosis. Its limitations including off-target effects, degradation, and poor cellular uptake might be mitigated by a nanocarrier system. MUC1, a transmembrane protein overexpressed in $\mathrm{LCa}$, aids the active targeting of drugs to the tumors. Perepelyuk and colleagues [105] synthesized mucin1-aptamer miRNA-29b- 
TABLE 1: Nanocarriers for cancer either in the market or in clinical trials.

\begin{tabular}{|c|c|c|c|c|c|}
\hline Commercial name (company) & Drug/agent & Delivery system & Indication & Status & Ref. \\
\hline $\begin{array}{l}\text { Doxil }^{\circledR} / \text { Caelyx }^{\mathrm{TM}} \text { (Schering- } \\
\text { Plough; Ortho Biotech) }\end{array}$ & Doxorubicin & Liposome & $\begin{array}{l}\text { Kaposi's sarcoma; ovarian } \\
\text { cancer; multiple myeloma }\end{array}$ & Approved & {$[68]$} \\
\hline $\begin{array}{l}\text { Myocet }^{\circledR} \text { (Sopherion; } \\
\text { Cephalon) }\end{array}$ & Doxorubicin & Liposome & Metastatic breast cancer & Approved & [68] \\
\hline Lipodox $^{\circledR}$ (Sun) & Doxorubicin & Liposome & Ovarian cancer & Approved & [69] \\
\hline DaunoXome ${ }^{\circledR}$ (Galen) & Daunorubicin & Liposome & Kaposi's sarcoma & Approved & {$[70]$} \\
\hline $\begin{array}{l}\text { Marqibo }^{\circledR} \text { (Talon; } \\
\text { Merrimack) }\end{array}$ & Vincristine & Liposome & $\begin{array}{c}\text { Acute lymphoblastic } \\
\text { leukemia }\end{array}$ & Approved & [68] \\
\hline Onivyde ${ }^{\circledR}$ (Ipsen) & Irinotecan & Liposome & Pancreatic cancer & Approved & [71] \\
\hline Oncaspar ${ }^{\circledR}$ (Enzon) & PEG-L-asparaginase & $\begin{array}{c}\text { Polymeric } \\
\text { nanoparticles }\end{array}$ & $\begin{array}{c}\text { Acute lymphoblastic } \\
\text { leukemia }\end{array}$ & Approved & [69] \\
\hline Eligard $^{\circledR}$ (Tolmar) & Leuprolide acetate & $\begin{array}{l}\text { Polymer (poly(DL- } \\
\text { lactide-co-glycolide) })\end{array}$ & Prostate cancer & Approved & {$[72]$} \\
\hline NanoTherm ${ }^{\circledR}$ (MagForce) & Iron oxide & Iron nanoparticles & Brain tumors & Approved & [73] \\
\hline $\begin{array}{l}\text { Abraxane }^{\circledR} \text { (Abraxis; } \\
\text { AstraZeneca) }\end{array}$ & Paclitaxel & $\begin{array}{l}\text { Albumin-bound } \\
\text { nanoparticles }\end{array}$ & Various cancers & Approved & {$[68]$} \\
\hline Rexin- $\mathrm{G}^{\circledR}$ (Epeius) & $\begin{array}{c}\text { Targeting protein marked } \\
\text { phospholipid @ miRNA-122 }\end{array}$ & Retrovector & $\begin{array}{c}\text { Osteosarcoma, pancreatic } \\
\text { cancer }\end{array}$ & Approved & [74] \\
\hline Ontak $^{\circledR}$ (Eisai) & $\begin{array}{c}\text { Diphtheria toxin and interleukin } \\
2 \text { bound to liposomes }\end{array}$ & Protein nanoparticles & T-cell lymphoma & Approved & {$[75]$} \\
\hline Vyxeos (Jazz) & Daunorubicin + cytarabine & Liposomes & Acute myeloid leukemia & Approved & [76] \\
\hline $\begin{array}{l}\text { Genexol-PM }{ }^{\otimes} \text { (Samyang } \\
\text { Biopharm) }\end{array}$ & Paclitaxel & Polymeric micelles & Ovarian cancer & Phase II & [68] \\
\hline LEP-ETU (NeoPharma) & Paclitaxel & Liposomes & Ovarian, breast, lung cancers & Phase I/II & {$[77]$} \\
\hline Paclical (Oasmia) & Paclitaxel & Micelles & Ovarian cancer & Phase III & [78] \\
\hline OSI-211 (OSI) & Lurtotecan & Liposomes & Lung, ovarian cancer & Phase II & [79] \\
\hline SGT-53 (SynerGene) & Wild-type p53 gene & Liposomes & $\begin{array}{l}\text { Solid tumors; glioblastoma; } \\
\text { pancreatic cancer }\end{array}$ & Phase II & {$[80]$} \\
\hline Atragen (Aronex) & All-trans-retinoic acid & Liposomal & $\begin{array}{c}\text { Acute promyelocytic } \\
\text { leukemia }\end{array}$ & Phase II & [79] \\
\hline Lipoplatin (Regulon) & Cisplatin & Liposomal & Various cancers & Phase III & [79] \\
\hline $\begin{array}{l}\text { Aurimmune (CytImmune } \\
\text { Sciences) }\end{array}$ & TNF- $\alpha$ & $\begin{array}{l}\text { Colloidal gold } \\
\text { nanoparticles }\end{array}$ & Solid tumors & Phase II & [79] \\
\hline NK012 (Nippon Kayaku) & $\begin{array}{l}\text { 7-Ethyl-10- } \\
\text { hydroxycamptothecin }\end{array}$ & Polymeric micelle & Advanced solid tumor & Phase II & [79] \\
\hline NK105 (Nippon Kayaku) & Paclitaxel & Micelles & Metastatic breast cancer & Phase III & [81] \\
\hline PEP02 (Merrimack) & Irinotecan & Liposomes & Advanced solid tumor & Phase I & [82] \\
\hline CriPec (Cristal) & Docetaxel & Polymeric micelles & Solid tumor & Phase I & [76] \\
\hline CRLX101 (Cerulean) & Camptothecin & $\begin{array}{l}\text { Cyclodextrin-based } \\
\text { nanoparticles }\end{array}$ & Non-small-cell lung cancer & $\begin{array}{l}\text { Phase II } \\
\text { completed }\end{array}$ & {$[75]$} \\
\hline ABI-009 (AADi) & Rapamycin & $\begin{array}{l}\text { Albumin-bound } \\
\text { nanoparticles }\end{array}$ & Bladder cancer & Phase I/II & [79] \\
\hline ThermoDox (Celsion) & Doxorubicin & $\begin{array}{l}\text { Thermal-sensitive } \\
\text { liposomes }\end{array}$ & Hepatocellular carcinoma & Phase III & [83] \\
\hline $\begin{array}{l}\text { CPX-351 (Fred Hutchinson } \\
\text { Research Center) }\end{array}$ & Cytarabine+daunorubicin & Liposomes & Acute myeloid leukemia & Phase I/II & [79] \\
\hline LiPlaCis (Oncology Venture) & Cisplatin & Liposomes & Various cancers & Phase II & [71] \\
\hline PLM60 (CSPC ZhongQi) & Mitoxantrone hydrochloride & Liposomes & $\begin{array}{l}\text { Non-Hodgkin lymphoma; } \\
\text { breast cancer }\end{array}$ & Phase I/II & [84] \\
\hline MM-302 (Merrimack) & Trastuzumab & Liposomes & Breast cancer & Phase I & [78] \\
\hline NBTXR3 (Nanobiotix) & Radiotherapy & $\begin{array}{l}\text { Hafnium oxide } \\
\text { nanoparticles }\end{array}$ & Liver cancer & Phase I/II & {$[76]$} \\
\hline
\end{tabular}


TABLE 1: Continued.

\begin{tabular}{lccccc}
\hline Commercial name (company) & Drug/agent & Delivery system & Indication & Status & Ref. \\
\hline Onco-TCS (Inex) & Vincristine & Liposomes & Non-Hodgkin's lymphoma & Phase I/II & [79] \\
Aroplatin (Antigenics) & Cisplatin analog & Liposomes & Colorectal cancer & Phase I/II & [79] \\
$\begin{array}{l}\text { EndoTAG-I (SynCore } \\
\text { Biotechnology) }\end{array}$ & Paclitaxel & Liposomes & Breast, pancreatic cancers & Phase II & [79] \\
Nektar-102 (Nektar) & Irinotecan & PEGylated liposome & Breast, colorectal cancers & Phase III & [79] \\
NKTR-105 (Nektar) & Docetaxel & PEG-docetaxel & Solid tumor & Phase I & [85] \\
\hline
\end{tabular}

loaded NPs which exhibited enhanced stability and delivery of miRNA-29b to LCa tissue in vivo, resulting in inhibited tumor growth.

An emerging area in lung cancer treatment is the inhalation delivery of NPs to improve tumor targeting. Inhaled Dox NPs exhibit lower cardiac side effects compared to the same standard dose of Dox after intratracheal administration, and paclitaxel-polyglutamic acid conjugates have been shown to be well tolerated by mice following intratracheal administration [106]. Studies in this area also highlight how lipid-based NPs display higher tumor accumulation and remain resident in the lungs for longer time periods postinhalation delivery. These and other inhalation-based nanocarriers hold promise for the effective delivery of anticancer agents specifically to lung tumors in the future.

Recent advancements in pharmaceutical nanotechnology have enabled formulation scientists to design surfaceengineered smart NP system for highly localized delivery of chemotherapeutic agents in cancerous tissues. A recent study reported PLGA-based dual-functionalized NP surface engineered with epidermal growth factor receptor (EGFR) aptamer for targeted delivery of homoharringtonine to lung cancer. The NPs were capable of delivering and releasing their loaded drug selectively to lung cancer cells due to their receptor recognition ability and responsiveness to glutathione present in the microenvironment of lung cancer [107].

3.1.2. Targeting Colon Cancer. Colon cancer is among the most common cancer types [108]. Patients with localized colon cancer typically receive surgery as the frontline treatment, and chemotherapy regimens are typically administered after surgery for $\sim 6$ months but their effectiveness remains limited. As the enhanced expression of CD98, a transmembrane glycoprotein, is a characteristic of the apical membranes of colon cancer cells, it is now established as a therapeutic target for drug delivery to colon tumors. To target this receptor, Xiao and colleagues [13] synthesized CD98-siRNA and camptothecin-loaded PEGylated Fab' ${ }^{\prime}$ NPs embedded in a hydrogel for colon targeting. The efficacy of the dual system was highlighted in mouse models of orthotropic colon tumors in which the therapeutic efficacy was higher than NPs containing a single drug due to higher drug internalization into the tumor cells.

A number of miRNAs display anticolon cancer activity in vitro, but their in vivo applications are limited by degradation in biofluids and limited cellular uptake. miR204-5p is significantly downregulated in colorectal cancer tissues compared with normal tissues. Using a surface- functionalizing technique, Zheng and colleagues [19] synthesized poly(D,L-lactide-co-glycolide)/poly(L-lactide)block-poly(ethylene glycol)-folate polymer NPs that were loaded with miR-204-5p and demonstrated their anticancer effects on colon cancer cells and xenograft colon tumor models in vivo. This study highlighted the NP system as a novel option for miRNA delivery to colon cancer cells in an in vivo setting.

Galectins are galactoside-binding proteins overexpressed in colorectal cancer and are involved in regulating its development, progression, and metastasis. In addition, they display high affinity for sugars such as galactose and lactose. Liu and colleagues [30] developed 5-fluorouracil-loaded mesoporous silica NP-based galactosylated chitosans as galectin-recognition materials for colon cancer-specific drug delivery. The NPs displayed a high loading capacity, sustained release, and increased cytotoxicity to human colon cancer cells compared to free 5-fluorouracil in vitro, demonstrating the efficacy of the inorganic-organic nanocomposite. Similarly, Jiang and coworkers prepared HA-conjugated mesoporous silica NPs loaded with 5-fluorouracil and demonstrated their cytotoxicity to colon cancer cells [109]. HA on the surface of NPs targeted the CD44 receptors overexpressed in the cancer cells.

Biotin is capable of targeted binding to biotin receptors overexpressed on the surfaces of colon cancer cells. So, Lin et al. [110] developed poly(ethylene glycol) and biotin-modified Dox-loaded silica NPs. Dox release from the NPs was redox-sensitive, and its tumor accumulation was potentiated in both HCT116 cells and tumor-bearing mice, enhancing its anticancer efficacy. In another study, the effects of silymarin (SLM), previously limited as an anticancer agent due to its low bioavailability, were enhanced using nanostructured SLM encapsulated in micelles. These NPs inhibited colon cancer cell growth and enhanced their apoptotic and necrotic indexes, with no effects on healthy colon cells [33].

Curcumin has been extensively shown to have anticancer properties, but its use is restricted by poor absorption, degradation, and rapid metabolism. In an interesting study by Alkhader and colleagues [111], curcumin was encapsulated into a chitosan-pectinate NP system (CUR-CS-PEC-NPs) to enhance its colon targeting ability. The NPs significantly enhanced the oral bioavailability of curcumin due to its protection from gastric degradation by pectin. These findings highlight the potential of the CUR-CS-PEC-NPs for oral delivery during colon cancer treatment and pave the way for the development of similar carriers to improve the tumor 


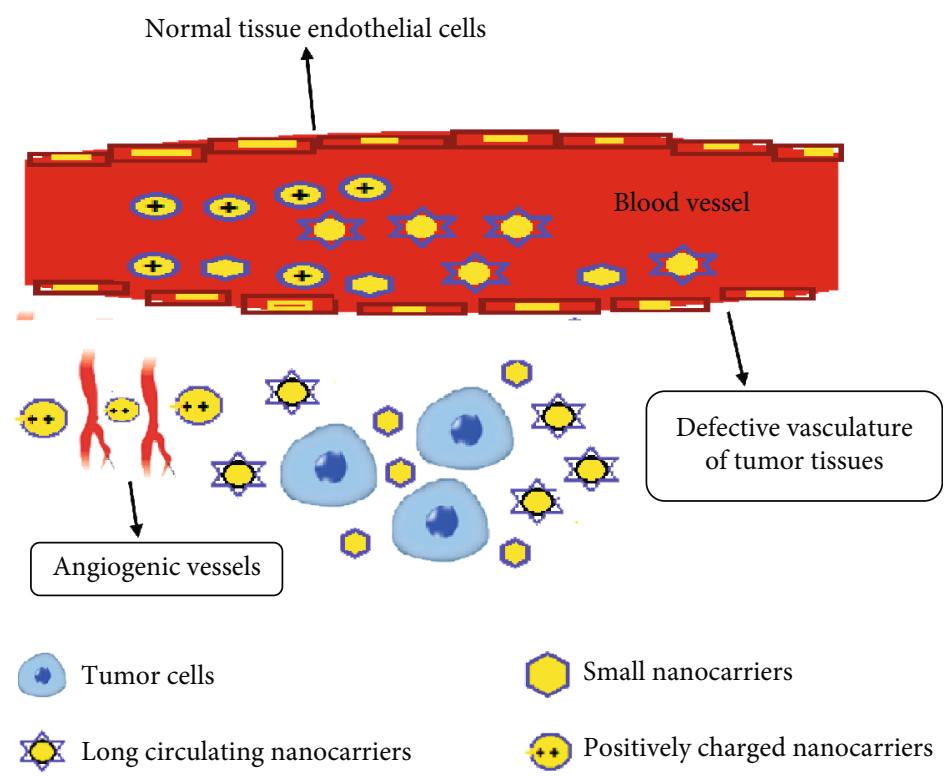

FIGURE 2: Schematic representation of passive anticancer drug targeting through nanocarriers.
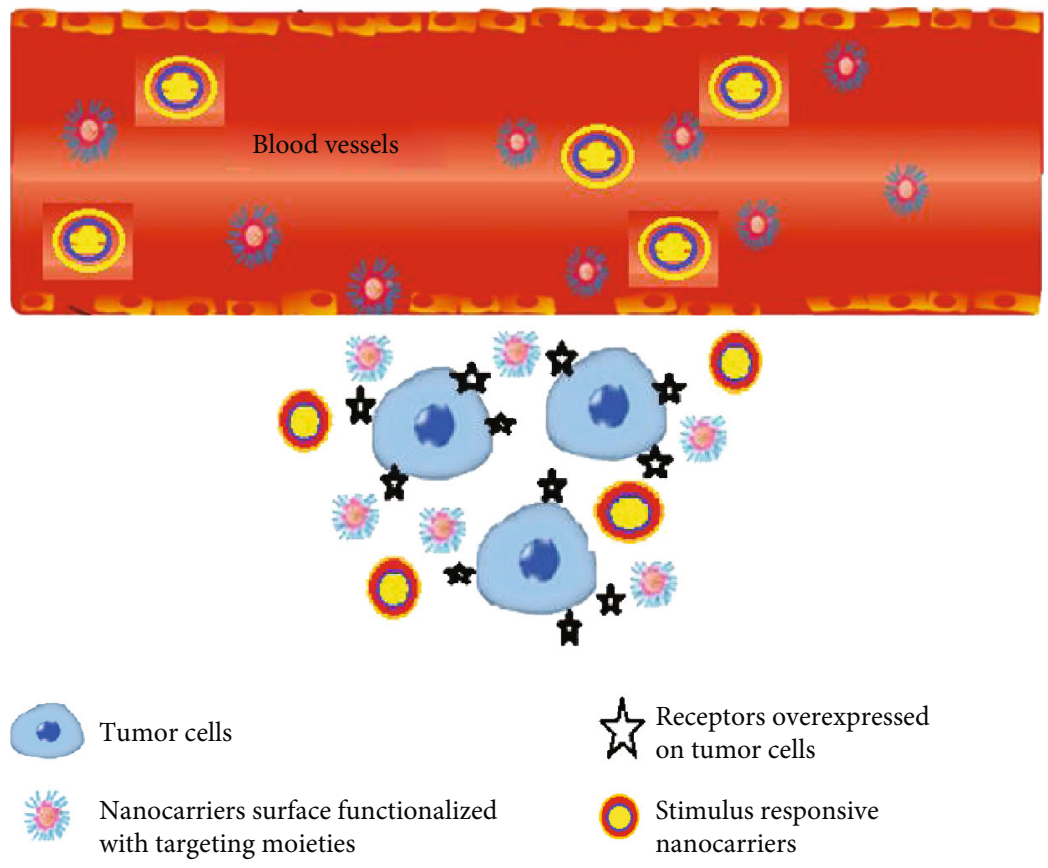

FIGURE 3: Schematic representation of active anticancer drug targeting through nanocarriers.

targeting of natural anticancer compounds. In another study, pH-responsive xylan-curcumin prodrug NPs were synthesized for improving curcumin anticancer efficacy against colon cancer. The synthesized NPs were capable of releasing their loaded drug at acidic $\mathrm{pH}$ owing to their $\mathrm{pH}$-responsive nature and increased the drug efficacy against human colon cancer cells as compared to pure drug [112]. A recent study has reported novel xylan-SS-curcumin redox-sensitive prodrug NPs for codelivery of curcumin and 5-fluorouracil against human colorectal cancer cells. Novel NPs were capable of increasing anticancer activity of their loaded drugs, showing them promising drug delivery systems for improved cancer therapy [113]. Another similar study reported xylan5-fluorouracil-1-acetic acid conjugates for colon cancer targeted therapy. Results revealed polymeric conjugates improved the drug anticancer efficacy against human colon cancer [114]. The same research group also reported improved anticancer activity for 5-fluorouracil against human colon cancer cells upon delivery in amphiphilic xylan-stearic acidbased NPs [115].

Colchicine is a natural alkaloid prodrug and acts as antimitotic anticancer agent; however, its cytotoxicity is a challenge for its effective anticancer efficacy. A recent study reported mesoporous silica NP surface functionalized with 
phosphonate groups and decorated with folic acid chitosan-glycine complex for colchicine effective delivery against colon cancer cells [116]. Enhanced anticancer activity of colchicine-laded NPs was proposed to be due to intrinsic apoptosis achieved via increased antimitotic activity. Another recent study reported targeted delivery of 5-fluorouracil $(5 \mathrm{Fu})$ and perfluorocarbon for effective treatment of colon cancer through epidermal growth factor(EGF-) functionalized PLGA NPs. The functionalized NPs were capable of selective localization of both the drugs into colon cancer cells and inhibited tumor growth through their ability of recognizing specific receptors present on colon cancer cells [117].

3.1.3. Targeting Cervical Cancer. Cervical cancer accounts for $\sim 3 \%$ of new cancer cases and the fourth most frequent cancer in women [1]. Several studies highlighted how NPs improve the activity of known anticancer drugs and natural products and enhance their efficacy against cervical cancer cell lines in vitro. However, in vivo studies on the effectiveness of these NPs remain limited. Silver NPs display antimicrobial, antiinflammatory, and anticancer activities. Al-Sheddi and coworkers [118] synthesized silver NPs using aqueous extracts of the plant Nepeta deflersiana and demonstrated their anticancer activity in HeLa cells through their ability to enhance ROS, lipid peroxidation, and subG1 cell cycle arrest. Yuan and colleagues investigated the synergistic effects of camptothecin, an inhibitor of topoisomerase with potent anticancer activity, and silver NPs on cultured human cervical cancer (HeLa cells) [15]. This combination was beneficial in the treatment of cervical cancer by altering the mitochondrial membrane permeability, increasing ROS formation, and activating caspases 9, 6, and 3. Hence, the combination of NPs and anticancer agents represents as a promising strategy in cancer research.

Regarding other nanomaterials, Luo and coworkers produced biotin-modified polylactic-co-glycolic acid NPs and demonstrated their ability to improve the antiproliferative effects of 15,16-dihydrotanshinone I in HeLa cells by decreasing intracellular ROS generation [31]. Transferrin has been extensively employed as a cancer cell-targeting molecule since transferrin receptor is overexpressed on cancer cells relative to normal cells. Boondireke and colleagues [119] enhanced the cytotoxicity of monomyristin, a monoacylglycerol from saw palmetto palm, in HeLa cells through its encapsulation into dextran-covered polylactide NPs conjugated to transferrin. Encapsulation and transferrin receptor targeting synergistically improved the water solubility and anticancer efficacy of monomyristin.

Cisplatin (CDDP) is an effective anticancer drug, but its lack of selectivity to cervical cancer tissue has limited its use. Therefore, Cheng and colleagues incorporated CDDP into fluorescein PEG amine grafted-aldehyde HA (Cy5.5PEG-g-A-HA) NPs to increase its selectivity for cervical cancer through tumoral acidic $\mathrm{pH}$ response [120]. Although HA is used as a targeting agent in nanocarriers, a major fraction might accumulate in the liver and might be cleared rapidly. The application of aldehyde HA (A-HA) in this study seems to have mitigated this issue. The experiments revealed favourable CDDP biocompatibility and cervical tumor targeting, with the NPs able to internalize and induce tumor cell apoptosis. Fluorescent imaging in vivo revealed high levels of CDDP-Cy5.5-PEG-g-A-HA accumulation at the cervical tumor site, thus demonstrating improved CDDP targeting.

A recent study reported development of $\mathrm{pH}$-sensitive lipid polymer conjugate NP surface decorated with folic acid for targeted delivery of paclitaxel and carboplatin to cervical cancer. The dual-functionalized NPs resulted in higher cellular uptake of the loaded drugs in cervical cancer cells and tumor inhibition via $\mathrm{pH}$-responsive drug release and receptor recognition [121]. Similarly, another recent study reported multifunctional layer-by-layer controlled released mesoporous $\mathrm{CaCO}_{3} \mathrm{NPs}$ for doxorubicin delivery to cervical cancer cells. The intelligent NPs were constructed with chitosan and sodium alginate as alternative materials, folic acid as cancer cell targeting ligand, and layer-by-layer as $\mathrm{pH}$-responsive approach. Cervical cancer cell-targeted delivery of doxorubicin was achieved in a controlled manner via $\mathrm{pH}$ responsiveness and receptor recognition [122]. Another recent study reported a novel bioinspired NP strategy for simultaneous delivery of paclitaxel and siRNA for effective treatment of cervical malignancies. Biomimetic dual-drug delivery system was designed through camouflaging HeLa cell membrane on PLGA NPs loaded with paclitaxel and siRNA. The innovative biomimetic dual-drug delivery system increased the drug selective tumor localization through immune escaping ability. As a result, almost $83 \%$ cervical tumor volume inhibition was achieved without side effects in major organs [123].

3.1.4. Targeting Breast Cancer. Breast cancer (BCa) is the second most frequent cancer and the leading cause of death in women globally [1]. Although photothermal therapy (PTT) is considered an attractive anticancer strategy, PTT-treated cancer cells may attain thermoresistance due to the upregulation of heat shock proteins (HSPs), mainly HSP70. Hence, inhibiting upregulated HSP70 may diminish the resistance of tumor cells to PTT. Quercetin, a dietary flavonoid, is not only a HSP70 inhibitor but also a protein kinase B and caspase 3 inhibitor. On the other hand, a cell membranecamouflaged system bestows NPs with powerful advantages. In this context, Zhao and colleagues produced macrophage membrane- (M-) camouflaged quercetin- (QE-) loaded hollow bismuth selenide NPs (M@BS-QE NPs) as a novel BCa therapeutic [17]. The M@BS-QE NPs remained resident in the circulation for longer time periods and enhanced $\mathrm{BCa}$ tumor drug accumulation through their ability to evade the immune system. A combination of macrophage membranes, quercetin, and bismuth-based NPs promoted active targeting, sensitized the tumor cells to phototherapy, and inhibited tumor invasiveness and metastasis. Actin cytoskeletal remodelling is highly correlated with tumor metastasis. Qin and colleagues designed novel small-sized fullerenol NPs that caused cytotoxicity in migratory BCa cells. The NPs could disturb actin cytoskeleton reorganization and dynamics in cancer cells and inhibited metastasis of aggressive BCa [124].

Dhanapal and Balaraman Ravindrran synthesized chitosan- and PLA-coated nanocarriers for piceatannol, a 
polyphenol with anticancer activity [24]. The degradation of chitosan was inhibited by combining it with the polymer PLA. These polymeric NPs provided a continuous release of the entrapped piceatannol, leading to higher cytotoxic efficacy for BCa and other cancer cell lines via mitochondriadependent pathways.

Kong et al. developed docetaxel- (DTX-) loaded cholic acid-functionalized AS1411 aptamer-polydopamine-poly( $\varepsilon$ caprolactone-ran-lactide) (CA(PCL-ran-PLA)) NPs which displayed potent in vitro and in vivo cytotoxicity in combination with photothermal treatment for BCa therapy [125]. With excellent biocompatibility and reduced side effects, these NPs appear promising for the synergistic chemophotothermal strategy of BCa. Shafiei-Irannejad et al. established that metformin, a biguanide antidiabetic drug, enhances the sensitivity of Dox-resistant BCa cells to Dox via inhibition of P-gp activity [126]. They synthesized biodegradable poly(lactide-co-glycolide)-D- $\alpha$-tocopheryl PEG 1000 succinate NPs encapsulating Dox and metformin, which displayed efficacy towards inactivation of resistant BCa cells [127]. Therefore, codelivery of Dox and metformin by polymeric NPs might be a promising approach to overcome MDR in BCa treatment.

Zeolitic imidazolate framework-8 (ZIF-8) is the most frequently employed MOF for $\mathrm{pH}$-responsive drug release, due to its porosity, sensitivity, and superior drug-loading capacity. Tian et al. fabricated fluorescein-ZIF-8/graphene oxide nanocrystals with acidic $\mathrm{pH}$-responsive release of fluorescein [128]. These nanocrystals inactivated breast cancer $4 \mathrm{~T} 1$ cells with high efficacy due to photothermal effect under near-infrared light. Chen and colleagues developed ATP-responsive Dox-loaded aptamer-gated nano-MOFs, which induced $40 \%$ and $55 \%$ cell death, respectively, within 5 days in MDA-MB-231 BCa cells [129]. They also reported a Dox-loaded ATP $/ \mathrm{Mg}^{2+}$-responsive $\mathrm{Zr}$-MOF which displayed selective cytotoxicity against MDA-MB-231 cells [130]. Due to overexpression of ATP in cancer cells, the aptamer targets the nucleolin receptor sites, leading to enhanced cell permeation of nano-MOFs.

A recent study reported multiwalled carbon nanotubes decorated with glycopolymers conjugated with folic acid for targeted delivery of doxorubicin for effective breast cancer therapy. Doxorubicin was selectively delivered to breast cancer cells through dual targeting of glucose transporter protein and folic acid receptors in breast cancer cells [131]. Another recent study reported methotrexate-loaded silica-coated gold NP system surface functionalized with folic acid for combined chemo-phototherapy of breast cancer. The nano system increased the effects of combined chemo-phototherapy selectively in breast cancer cells due to its selective delivery via folic acid receptor recognition overexpressed on the surfaces of those cancer cells [132]. Furthermore, another recent study reported dual targeting polymeric NPs for selective delivery of paclitaxel for the treatment of bone metastatic breast cancer. The NPs were decorated with folic acid and alendronate-modified D- $\alpha$ tocopheryl polyethylene glycol succinate for achieving dual drug targeting. The novel system showed binding affinity for hydroxyapatite followed by receptor-mediated internal- ization, thus showing greater therapeutic effects for the drug against bone metastatic cancer through inhibition of tumor growth and increasing survival rate [133].

\section{Conclusion and Future Perspectives}

Chemotherapy is preferred for effective treatment of various types of cancer due to its noninvasive nature and killing of cancerous cells. However, optimum clinical efficacy of chemotherapeutics cannot be achieved due to their unique physicochemical properties and lack of target selectivity. As a result, minimum anticancer efficacy is achieved at the cost of massive contamination of the rest of the body, thus leading to severe off-target side effects. Furthermore, the tumor microenvironment also presents various obstacles due to its abnormal pathophysiology. Due to their small size and modulated physicochemical properties, nanocarriers are now established as materials that can be increasingly utilized in cancer therapeutics. In particular, stimuli-responsive and surface-engineered targeted nanocarriers that release their payloads at the tumor site are of particular interest to cancer therapy. Recent advances in the field of pharmaceutical nanotechnology have led formulation scientists to develop smart nanocarrier-based targeted delivery systems for effective treatment and management of lung, colon, cervical, and breast cancers. Published reports show that various types of nanocarriers including liposomes, lipid, metal and polymeric NPs and micelles, nano-MOFs, and carbon nanotubes have been effectively used for targeted delivery of chemotherapeutic agents for lung, colon, cervical, and breast cancer treatment. Various types of surfacefunctionalized nanocarriers such as high redox status, acidic $\mathrm{pH}$, or hypoxia-responsive NPs have also been reported for overcoming the barriers of the tumor microenvironment and selective localization of anticancer drugs in lung, colon, cervical, and breast tumors. Recently, several nanodrugs have received FDA approval, and many more are in clinical trials. Most of the presently approved nanodrugs are based on approved conventional drugs and simple NPs.

However, the lack of standard protocols for nanocarrier and nanodrug characterization toxicity, physical, chemical, and biological instability, disease heterogeneity, and irregular in vivo behaviour of NPs frequently restrict the efforts of researchers, thus leading to NP failure in late-phase clinical trials. To prevent their failure in clinical trials, it is crucial to understand the cancer heterogeneity and inherent properties of NPs so they can be effectively modulated for increasing their stability and biocompatibility and uniform in vivo behaviour. Similarly, research in nanomedicine for lung, colon, cervical, and breast cancer treatment is mostly focused on material and formulation investigations which represent the preliminary stages. Data for their potential applications as therapeutics needs to be acquired only from animal studies, and multidisciplinary approaches should be adopted. With the global trend towards precision medicine, the future for a multicentered strategy of nanocarrier technology appears promising. Furthermore, regularity procedures also remain as major obstacles; thus, an easy and integrated approval procedure approach should be designed. 
Nevertheless, nanodrug platforms are incorporating a broad range of NP types and becoming more complex. The research occurring in this arena predicts the availability of numerous new nanodrugs for clinical use in the future. Intelligent NP systems capable of simultaneous targeted chemotherapy, disease monitoring, and diagnosis can also be predicted from the current advancements being made in this area. Although many challenges complicate nanodrug development, it may only be a matter of time until these agents offer unique solutions for unmet clinical needs.

\section{Conflicts of Interest}

All the authors declare no conflict of interest.

\section{Authors' Contributions}

Ke-Tao Jin and Ze-Bei Lu contributed equally to this work.

\section{Acknowledgments}

This work was supported by the Zhejiang Provincial Science and Technology Projects (No. LGF18H160026 to YYZ, No. LGD19H160001 to JKT, and No. LGF20H140010 to FY), the National Natural Science Foundation of China (No. 81772537 to JKT and No. 81374014 to JKT), the Zhejiang Provincial Natural Science Foundation of China (No. LY17H180010 to XYC and No. LY15H160055 to HYD), and the Zhejiang Medical Technology Plan Project (No. 2015KYA023 to HYD).

\section{References}

[1] M. M. Fidler, F. Bray, and I. Soerjomataram, "The global cancer burden and human development: a review," Scandinavian Journal of Public Health, vol. 46, no. 1, pp. 27-36, 2018.

[2] J. L. Caswell-Jin, S. K. Plevritis, L. Tian et al., "Change in survival in metastatic breast cancer with treatment advances: meta-analysis and systematic review," JNCI Cancer Spectrum, vol. 2, no. 4, article pky062, 2018.

[3] M. Fardi, S. Solali, and M. Farshdousti Hagh, "Epigenetic mechanisms as a new approach in cancer treatment: an updated review," Genes \& Diseases, vol. 5, no. 4, pp. 304311, 2018.

[4] A. Guglielmo, N. Staropoli, M. Giancotti, and M. Mauro, "Personalized medicine in colorectal cancer diagnosis and treatment: a systematic review of health economic evaluations," Cost Effectiveness and Resource Allocation, vol. 16, no. 1, p. 2, 2018.

[5] X. Guo, Q. Zhuang, T. Ji et al., "Multi-functionalized chitosan nanoparticles for enhanced chemotherapy in lung cancer," Carbohydrate Polymers, vol. 195, pp. 311-320, 2018.

[6] H. I. Tsai, L. Jiang, X. Zeng et al., "DACHPt-loaded nanoparticles self-assembled from biodegradable dendritic copolymer polyglutamic acid-b-D- $\alpha$-tocopheryl polyethylene glycol 1000 succinate for multidrug resistant lung cancer therapy," Frontiers in Pharmacology, vol. 9, p. 119, 2018.

[7] S. Rangaraj and R. Venkatachalam, "In vitroandin vivocharacteristics of biogenic high surface silica nanoparticles in A549 lung cancer cell lines andDanio reriomodel systems for inorganic biomaterials development,"
Artificial Cells, Nanomedicine, and Biotechnology, vol. 46, no. 7, pp. 1415-1424, 2017.

[8] P. Rychahou, Y. Bae, D. Reichel et al., "Colorectal cancer lung metastasis treatment with polymer-drug nanoparticles," Journal of Controlled Release, vol. 275, pp. 85-91, 2018.

[9] H. Shali, M. Shabani, F. Pourgholi et al., "Co-delivery of insulin-like growth factor 1 receptor specific siRNA and doxorubicin using chitosan-based nanoparticles enhanced anticancer efficacy in A549 lung cancer cell line," Artificial Cells, Nanomedicine, and Biotechnology, vol. 46, no. 2, pp. 293-302, 2017.

[10] A. Sharma, B. Gorey, and A. Casey, "In vitro comparative cytotoxicity study of aminated polystyrene, zinc oxide and silver nanoparticles on a cervical cancer cell line," Drug and Chemical Toxicology, vol. 42, no. 1, pp. 9-23, 2018.

[11] Y. Shoja, A. Kermanpur, and F. Karimzadeh, "Diagnosis of EGFR exon21 L858R point mutation as lung cancer biomarker by electrochemical DNA biosensor based on reduced graphene oxide/functionalized ordered mesoporous carbon/Ni-oxytetracycline metallopolymer nanoparticles modified pencil graphite electrode," Biosensors \& Bioelectronics, vol. 113, pp. 108-115, 2018.

[12] Y. Song, H. Cai, T. Yin et al., "Paclitaxel-loaded redoxsensitive nanoparticles based on hyaluronic acid-vitamin $\mathrm{E}$ succinate conjugates for improved lung cancer treatment," International Journal of Nanomedicine, vol. Volume 13, pp. 1585-1600, 2018.

[13] B. Xiao, E. Viennois, Q. Chen et al., "Silencing of intestinal glycoprotein CD98 by orally targeted nanoparticles enhances chemosensitization of colon cancer," ACS Nano, vol. 12, no. 6, pp. 5253-5265, 2018.

[14] R. Yokchom, S. Laiwejpithaya, W. Maneeprakorn, S. Tapaneeyakorn, J. Rabablert, and T. Dharakul, "Paperbased immunosensor with signal amplification by enzymelabeled anti-p16INK4a multifunctionalized gold nanoparticles for cervical cancer screening," Nanomedicine, vol. 14, no. 3, pp. 1051-1058, 2018.

[15] Y. G. Yuan, S. Zhang, J. Y. Hwang, and I. K. Kong, "Silver nanoparticles potentiates cytotoxicity and apoptotic potential of camptothecin in human cervical cancer cells," Oxidative Medicine and Cellular Longevity, vol. 2018, Article ID 6121328, 21 pages, 2018.

[16] X. Zhang and C. Xiao, "Biofabrication of silver nanoparticles and their combined effect with low intensity ultrasound for treatment of lung cancer," Journal of Photochemistry and Photobiology. B, vol. 181, pp. 122-126, 2018.

[17] H. Zhao, L. Li, J. Zhang et al., "C-C chemokine ligand 2 (CCL2) recruits macrophage-membrane-camouflaged hollow bismuth selenide nanoparticles to facilitate photothermal sensitivity and inhibit lung metastasis of breast cancer," ACS Applied Materials \& Interfaces, vol. 10, no. 37, pp. 3112431135, 2018.

[18] Y. Zhao, Q. Sun, X. Zhang, J. Baeyens, and H. Su, "Self-assembled selenium nanoparticles and their application in the rapid diagnostic detection of small cell lung cancer biomarkers," Soft Matter, vol. 14, no. 4, pp. 481-489, 2018.

[19] B. Zheng, L. Chen, C. C. Pan et al., "Targeted delivery of miRNA-204-5p by PEGylated polymer nanoparticles for colon cancer therapy," Nanomedicine, vol. 13, no. 7, pp. 769-785, 2018.

[20] D. Zheng, J. Wang, S. Guo, Z. Zhao, and F. Wang, "Formulations, pharmacodynamic and clinical studies of nanoparticles 
for lung cancer therapy - an overview," Current Drug Metabolism, vol. 19, no. 9, pp. 759-767, 2018.

[21] C. Conte, F. Mastrotto, V. Taresco et al., "Enhanced uptake in $2 \mathrm{D}$ - and $3 \mathrm{D}$ - lung cancer cell models of redox responsive PEGylated nanoparticles with sensitivity to reducing extraand intracellular environments," Journal of Controlled Release, vol. 277, pp. 126-141, 2018.

[22] W. Chengzheng, W. Jiazhi, C. Shuangjiang et al., "Biogenic synthesis, characterization and evaluation of silver nanoparticles from Aspergillus niger JX556221 against human colon cancer cell line HT-29," Journal of Nanoscience and Nanotechnology, vol. 18, no. 5, pp. 3673-3681, 2018.

[23] N. Dasgupta, S. Ranjan, D. Mishra, and C. Ramalingam, "Thermal co-reduction engineered silver nanoparticles induce oxidative cell damage in human colon cancer cells through inhibition of reduced glutathione and induction of mitochondria-involved apoptosis," Chemico-Biological Interactions, vol. 295, pp. 109-118, 2018.

[24] J. Dhanapal and M. Balaraman Ravindrran, "Chitosan/poly (lactic acid)-coated piceatannol nanoparticles exert anin vitroapoptosis activity on liver, lung and breast cancer cell lines," Artificial Cells, Nanomedicine, and Biotechnology, vol. 46, supplement 1, pp. 274-282, 2018.

[25] N. Dudhipala and G. Puchchakayala, "Capecitabine lipid nanoparticles for anti-colon cancer activity in 1,2-dimethylhydrazine-induced colon cancer: preparation, cytotoxic, pharmacokinetic, and pathological evaluation," Drug Development and Industrial Pharmacy, vol. 44, no. 10, pp. 15721582, 2018.

[26] N. Gonzalez-Ballesteros, M. C. Rodriguez-Arguelles, S. Prado-Lopez et al., "Macroalgae to nanoparticles: study of Ulva lactuca L. role in biosynthesis of gold and silver nanoparticles and of their cytotoxicity on colon cancer cell lines," Materials Science \& Engineering. C, Materials for Biological Applications, vol. 97, pp. 498-509, 2019.

[27] S. Gurunathan, M. Qasim, C. Park, H. Yoo, J. H. Kim, and K. Hong, "Cytotoxic potential and molecular pathway analysis of silver nanoparticles in human colon cancer cells HCT116," International Journal of Molecular Sciences, vol. 19, no. 8, p. 2269, 2018.

[28] S. Handali, E. Moghimipour, M. Rezaei, S. Saremy, and F. A. Dorkoosh, "Co-delivery of 5-fluorouracil and oxaliplatin in novel poly(3-hydroxybutyrate-co-3-hydroxyvalerate acid)/poly(lactic-co-glycolic acid) nanoparticles for colon cancer therapy," International Journal of Biological Macromolecules, vol. 124, pp. 1299-1311, 2019.

[29] F. T. Hsu, H. S. Liu, A. A. A. Ali et al., "Assessing the selective therapeutic efficacy of superparamagnetic erlotinib nanoparticles in lung cancer by using quantitative magnetic resonance imaging and a nuclear factor kappa-B reporter gene system," Nanomedicine, vol. 14, no. 3, pp. 1019-1031, 2018.

[30] W. Liu, Y. Zhu, F. Wang et al., "Galactosylated chitosanfunctionalized mesoporous silica nanoparticles for efficient colon cancer cell-targeted drug delivery," Royal Society Open Science, vol. 5, no. 12, article 181027, 2018.

[31] J. Luo, X. Meng, J. Su et al., "Biotin-modified polylactic-coglycolic acid nanoparticles with improved antiproliferative activity of 15,16-dihydrotanshinone I in human cervical cancer cells," Journal of Agricultural and Food Chemistry, vol. 66, no. 35, pp. 9219-9230, 2018.

[32] J. Marquez, I. Fernandez-Pineiro, M. J. Arauzo-Bravo et al., "Targeting liver sinusoidal endothelial cells with miR-20a- loaded nanoparticles reduces murine colon cancer metastasis to the liver," International Journal of Cancer, vol. 143, no. 3, pp. 709-719, 2018.

[33] M. Mombeini, G. Saki, L. Khorsandi, and N. Bavarsad, "Effects of silymarin-loaded nanoparticles on HT-29 human colon cancer cells," Medicina, vol. 54, no. 1, p. 1, 2018.

[34] M. Moskvin, M. Babic, S. Reis et al., "Biological evaluation of surface-modified magnetic nanoparticles as a platform for colon cancer cell theranostics," Colloids and Surfaces. B, Biointerfaces, vol. 161, pp. 35-41, 2018.

[35] L. Pan, F. Ye, J. J. Liu, X. Q. Ba, and Q. S. Sheng, "A study of using carbon nanoparticles to improve lymph nodes staging for laparoscopic-assisted radical right hemicolectomy in colon cancer," International Journal of Colorectal Disease, vol. 33, no. 8, pp. 1131-1134, 2018.

[36] Z. Song, Y. Shi, Q. Han, and G. Dai, "Endothelial growth factor receptor-targeted and reactive oxygen species-responsive lung cancer therapy by docetaxel and resveratrol encapsulated lipid-polymer hybrid nanoparticles," Biomedicine \& Pharmacotherapy, vol. 105, pp. 18-26, 2018.

[37] C. E. Swenson, D. Haemmerich, D. H. Maul, B. Knox, N. Ehrhart, and R. A. Reed, "Increased duration of heating boosts local drug deposition during radiofrequency ablation in combination with thermally sensitive liposomes (ThermoDox) in a porcine model," PloS one, vol. 10, no. 10, article e0139752, 2015.

[38] A. A. Attama, M. A. Momoh, and P. F. Builders, "Lipid nanoparticulate drug delivery systems: a revolution in dosage form design and development," Recent advances in novel drug carrier systems, vol. 5, pp. 107-140, 2012.

[39] L. Genc, H. M. Kutlu, and G. Guney, "Vitamin B12-loaded solid lipid nanoparticles as a drug carrier in cancer therapy," Pharmaceutical Development and Technology, vol. 20, no. 3, pp. 337-344, 2013.

[40] O. S. Muddineti, A. Shah, S. V. K. Rompicharla, B. Ghosh, and S. Biswas, "Cholesterol-grafted chitosan micelles as a nanocarrier system for drug-siRNA co-delivery to the lung cancer cells," International Journal of Biological Macromolecules, vol. 118, Part A, pp. 857-863, 2018.

[41] Y. Shen, J. Zhang, W. Hao et al., "Copolymer micelles function as $\mathrm{pH}$-responsive nanocarriers to enhance the cytotoxicity of a HER2 aptamer in HER2-positive breast cancer cells," International Journal of Nanomedicine, vol. Volume 13, pp. 537-553, 2018.

[42] Y. Guo, W. He, S. Yang, D. Zhao, Z. Li, and Y. Luan, "Codelivery of docetaxel and verapamil by reduction-sensitive PEG-PLGA-SS-DTX conjugate micelles to reverse the multi-drug resistance of breast cancer," Colloids and Surfaces. B, Biointerfaces, vol. 151, pp. 119-127, 2017.

[43] Z. Li, H. Wang, Y. Chen et al., "pH- and NIR light-responsive polymeric prodrug micelles for hyperthermia-assisted sitespecific chemotherapy to reverse drug resistance in cancer treatment," Small, vol. 12, no. 20, pp. 2731-2740, 2016.

[44] L. Lv, K. Qiu, X. Yu et al., “Amphiphilic copolymeric micelles for doxorubicin and curcumin co-delivery to reverse multidrug resistance in breast cancer," Journal of Biomedical Nanotechnology, vol. 12, no. 5, pp. 973-985, 2016.

[45] K. Liang, J. E. Chung, S. J. Gao, N. Yongvongsoontorn, and M. Kurisawa, "Highly augmented drug loading and stability of micellar nanocomplexes composed of doxorubicin and poly(ethylene glycol)-green tea catechin conjugate for cancer 
therapy," Advanced Materials, vol. 30, no. 14, article e1706963, 2018.

[46] S. Movassaghian, O. M. Merkel, and V. P. Torchilin, "Applications of polymer micelles for imaging and drug delivery," Wiley Interdisciplinary Reviews: Nanomedicine and Nanobiotechnology, vol. 7, no. 5, pp. 691-707, 2015.

[47] T. Li, S. Shi, S. Goel et al., "Recent advancements in mesoporous silica nanoparticles towards therapeutic applications for cancer," Acta Biomaterialia, vol. 89, pp. 1-13, 2019.

[48] D. Eom, J. Kim, K. Lee et al., "Fabrication of AlN nanostructures using polarity control by high temperature metalorganic chemical vapor deposition," Journal of Nanoscience and Nanotechnology, vol. 15, no. 7, pp. 51445147, 2015.

[49] N. Bhardwaj, S. K. Pandey, J. Mehta, S. K. Bhardwaj, K. H. Kim, and A. Deep, "Bioactive nano-metal-organic frameworks as antimicrobials against Gram-positive and Gramnegative bacteria," Toxicology Research, vol. 7, no. 5, pp. 931-941, 2018.

[50] B. Khezri and M. Pumera, "Metal-organic frameworks based nano/micro/millimeter-sized self-propelled autonomous machines," Advanced Materials, vol. 31, no. 14, article e1806530, 2019.

[51] E. Calzoni, A. Cesaretti, A. Polchi, A. Di Michele, B. Tancini, and C. Emiliani, "Biocompatible polymer nanoparticles for drug delivery applications in cancer and neurodegenerative disorder therapies," Journal of Functional Biomaterials, vol. 10, no. 1, p. 4, 2019.

[52] H. Choudhury, M. Pandey, P. X. Chin et al., "Transferrin receptors-targeting nanocarriers for efficient targeted delivery and transcytosis of drugs into the brain tumors: a review of recent advancements and emerging trends," Drug Delivery and Translational Research, vol. 8, no. 5, pp. 1545-1563, 2018.

[53] B. Deng, P. Ma, and Y. Xie, "Reduction-sensitive polymeric nanocarriers in cancer therapy: a comprehensive review," Nanoscale, vol. 7, no. 30, pp. 12773-12795, 2015.

[54] R. M. Farid, N. A. H. A. Youssef, and A. A. Kassem, "Platform for lipid based nanocarriers' formulation components and their potential effects: a literature review," Current Pharmaceutical Design, vol. 23, no. 43, pp. 6613-6629, 2018.

[55] M. Fojtu, J. Gumulec, T. Stracina et al., "Reduction of doxorubicin-induced cardiotoxicity using nanocarriers: a review," Current Drug Metabolism, vol. 18, no. 3, pp. 237263, 2017.

[56] Y. C. Barenholz, "Doxil ${ }^{\circledR}$ - The first FDA-approved nanodrug: Lessons learned," Journal of Controlled Release, vol. 160, no. 2, pp. 117-134, 2012.

[57] A. Cadete and M. J. Alonso, "Targeting cancer with hyaluronic acid-based nanocarriers: recent advances and translational perspectives," Nanomedicine, vol. 11, no. 17, pp. 2341-2357, 2016.

[58] W. Q. Lim, S. Z. F. Phua, H. V. Xu, S. Sreejith, and Y. Zhao, "Recent advances in multifunctional silica-based hybrid nanocarriers for bioimaging and cancer therapy," Nanoscale, vol. 8, no. 25, pp. 12510-12519, 2016.

[59] G. K. Rout, H.-S. Shin, S. Gouda et al., "Current advances in nanocarriers for biomedical research and their applications," Artificial Cells, Nanomedicine, and Biotechnology, vol. 46, supplement 2, pp. 1053-1062, 2018.
[60] X. Yue and Z. Dai, "Recent advances in liposomal nanohybrid cerasomes as promising drug nanocarriers," Advances in Colloid and Interface Science, vol. 207, pp. 32-42, 2014.

[61] N. Desai, "Nanoparticle albumin-bound paclitaxel (Abraxane $\left.{ }^{\circledR}\right)$, in Albumin in Medicine, pp. 101-119, Springer, 2016.

[62] A. Garg, R. Sharma, V. Pandey, V. Patel, and A. K. Yadav, "Heparin-tailored biopolymeric nanocarriers in site-specific delivery: a systematic review," Critical Reviews in Therapeutic Drug Carrier Systems, vol. 34, no. 1, pp. 1-33, 2017.

[63] M. Moreno-Sastre, M. Pastor, C. J. Salomon, A. Esquisabel, and J. L. Pedraz, "Pulmonary drug delivery: a review on nanocarriers for antibacterial chemotherapy," The Journal of Antimicrobial Chemotherapy, vol. 70, no. 11, pp. 2945-2955, 2015.

[64] S. M. Mousavi, S. A. Hashemi, Y. Ghasemi, A. M. Amani, A. Babapoor, and O. Arjmand, "Applications of graphene oxide in case of nanomedicines and nanocarriers for biomolecules: review study," Drug Metabolism Reviews, vol. 51, no. 1, pp. 12-41, 2019.

[65] J. V. Natarajan, C. Nugraha, X. W. Ng, and S. Venkatraman, "Sustained-release from nanocarriers: a review," Journal of Controlled Release, vol. 193, pp. 122-138, 2014.

[66] N. Olov, S. Bagheri-Khoulenjani, and H. Mirzadeh, "Combinational drug delivery using nanocarriers for breast cancer treatments: a review," Journal of Biomedical Materials Research. Part A, vol. 106, no. 8, pp. 2272-2283, 2018.

[67] S. Pimentel-Moral, M. C. Teixeira, A. R. Fernandes et al., "Lipid nanocarriers for the loading of polyphenols - a comprehensive review," Advances in Colloid and Interface Science, vol. 260, pp. 85-94, 2018.

[68] A. Smith, Big Moment for Nanotech: Oncology Therapeutics Poised for a Leap, 2013, OncLive.

[69] R. Bawa, G. F. Audette, and I. Rubinstein, "Copaxone ${ }^{\circledR}$ in the era of biosimilars and nanosimilars," in Handbook of Clinical Nanomedicine, pp. 829-872, Jenny Stanford Publishing, 2016.

[70] L. Chen, H. Shiah, T. Chao et al., "Phase I study of liposome irinotecan (PEP02) in combination with weekly infusion of 5FU/LV in advanced solid tumors," Journal of Clinical Oncology, vol. 28, 15, pp. e13024-e13024, 2010.

[71] S. Tran, P.-J. DeGiovanni, B. Piel, and P. Rai, "Cancer nanomedicine: a review of recent success in drug delivery," Clinical and Translational Medicine, vol. 6, no. 1, p. 44, 2017.

[72] S. Rezvantalab, N. I. Drude, M. K. Moraveji et al., "PLGAbased nanoparticles in cancer treatment," Frontiers in Pharmacology, vol. 9, p. 1260, 2018.

[73] G. Ledet and T. K. Mandal, "Nanomedicine: emerging therapeutics for the 21st century," U.S. Pharmacist, vol. 37, no. 3, pp. 7-11, 2012.

[74] R. Wang, P. S. Billone, and W. M. Mullett, "Nanomedicine in action: an overview of cancer nanomedicine on the market and in clinical trials," Journal of Nanomaterials, vol. 2013, 12 pages, 2013.

[75] D. Bobo, K. J. Robinson, J. Islam, K. J. Thurecht, and S. R. Corrie, "Nanoparticle-based medicines: a review of FDAapproved materials and clinical trials to date," Pharmaceutical Research, vol. 33, no. 10, pp. 2373-2387, 2016.

[76] A. C. Anselmo and S. Mitragotri, "Nanoparticles in the clinic: an update," Bioengineering \& Translational Medicine, vol. 4, no. 3, article e10143, 2019. 
[77] E. Beltrán-Gracia, A. López-Camacho, I. Higuera-Ciapara, J. B. Velázquez-Fernández, and A. A. Vallejo-Cardona, "Nanomedicine review: clinical developments in liposomal applications," Cancer Nanotechnology, vol. 10, no. 1, p. 11, 2019.

[78] C. L. Ventola, "Progress in nanomedicine: approved and investigational nanodrugs," Pharmacy and Therapeutics, vol. 42, no. 12, p. 742, 2017.

[79] I. Ali, M. Alsehli, L. Scotti et al., "Progress in polymeric nanomedicines for theranostic cancer treatment," Polymers, vol. 12, no. 3, p. 598, 2020.

[80] N. Senzer, J. Nemunaitis, D. Nemunaitis et al., "Phase I study of a systemically delivered p53 nanoparticle in advanced solid tumors," Molecular Therapy, vol. 21, no. 5, pp. 1096-1103, 2013.

[81] K. Kato, K. Chin, T. Yoshikawa et al., "Phase II study of NK105, a paclitaxel-incorporating micellar nanoparticle, for previously treated advanced or recurrent gastric cancer," Investigational New Drugs, vol. 30, no. 4, pp. 1621-1627, 2012.

[82] N.-J. Chiang, T.-Y. Chao, R.-K. Hsieh et al., "A phase I doseescalation study of PEP02 (irinotecan liposome injection) in combination with 5-fluorouracil and leucovorin in advanced solid tumors," BMC Cancer, vol. 16, no. 1, p. 907, 2016.

[83] M. Z. El-Readi and M. A. Althubiti, "Cancer nanomedicine: a new era of successful targeted therapy," Journal of Nanomaterials, vol., vol. 2019, article 4927312, 2019.

[84] V. Thakur and R. V. Kutty, "Recent advances in nanotheranostics for triple negative breast cancer treatment," Journal of Experimental \& Clinical Cancer Research, vol. 38, no. 1, p. 430, 2019.

[85] S. Parveen, F. Arjmand, and S. Tabassum, "Clinical developments of antitumor polymer therapeutics," RSC Advances, vol. 9, no. 43, pp. 24699-24721, 2019.

[86] X. Chi, K. Liu, X. Luo, Z. Yin, H. Lin, and J. Gao, "Recent advances of nanomedicines for liver cancer therapy," Journal of Materials Chemistry B, vol. 8, no. 17, pp. 3747-3771, 2020.

[87] S. Khan, M. Imran, T. T. Butt et al., "Curcumin based nanomedicines as efficient nanoplatform for treatment of cancer: new developments in reversing cancer drug resistance, rapid internalization, and improved anticancer efficacy," Trends in Food Science \& Technology, vol. 80, pp. 8-22, 2018.

[88] G. W. Sledge and K. D. Miller, "Exploiting the hallmarks of cancer: the future conquest of breast cancer," European Journal of Cancer, vol. 39, no. 12, pp. 1668-1675, 2003.

[89] B. A. Teicher, "Molecular targets and cancer therapeutics: discovery, development and clinical validation," Drug Resistance Updates, vol. 3, no. 2, pp. 67-73, 2000.

[90] L. Basile, R. Pignatello, and C. Passirani, "Active targeting strategies for anticancer drug nanocarriers," Current Drug Delivery, vol. 9, no. 3, pp. 255-268, 2012.

[91] S. K. Hobbs, W. L. Monsky, F. Yuan et al., "Regulation of transport pathways in tumor vessels: role of tumor type and microenvironment," Proceedings of the National Academy of Sciences, vol. 95, no. 8, pp. 4607-4612, 1998.

[92] P. Rubin and G. Casarett, "Microcirculation of tumors part II: the supervascularized state of irradiated regressing tumors," Clinical Radiology, vol. 17, no. 4, pp. 346-355, 1966.

[93] B. Haley and E. Frenkel, "Nanoparticles for drug delivery in cancer treatment," in Urologic Oncology: Seminars and original investigations, pp. 57-64, Elsevier, 2008.
[94] D. C. Drummond, O. Meyer, K. Hong, D. B. Kirpotin, and D. Papahadjopoulos, "Optimizing liposomes for delivery of chemotherapeutic agents to solid tumors," Pharmacological Reviews, vol. 51, no. 4, pp. 691-743, 1999.

[95] A. A. Gabizon, "Pegylated liposomal doxorubicin: metamorphosis of an old drug into a new form of chemotherapy," Cancer Investigation, vol. 19, no. 4, pp. 424-436, 2001.

[96] G. P. Adams, R. Schier, A. M. McCall et al., "High affinity restricts the localization and tumor penetration of singlechain fv antibody molecules," Cancer Research, vol. 61, no. 12, pp. 4750-4755, 2001.

[97] S. Gosk, T. Moos, C. Gottstein, and G. Bendas, "VCAM-1 directed immunoliposomes selectively target tumor vasculature in vivo," Biochimica et Biophysica Acta (BBA)-Biomembranes, vol. 1778, no. 4, pp. 854-863, 2008.

[98] M. Radovic, R. Kanesvaran, A. Rittmeyer et al., "Multidisciplinary treatment of lung cancer in older patients: a review," Journal of Geriatric Oncology, vol. 10, no. 3, pp. 405-410, 2019.

[99] L. M. Hess, A. M. DeLozier, F. Natanegara et al., "First-line treatment of patients with advanced or metastatic squamous non-small cell lung cancer: systematic review and network meta-analysis," Journal of Thoracic Disease, vol. 10, no. 12, pp. 6677-6694, 2018.

[100] V. Ramalingam, K. Varunkumar, V. Ravikumar, and R. Rajaram, "Target delivery of doxorubicin tethered with PVP stabilized gold nanoparticles for effective treatment of lung cancer," Scientific Reports, vol. 8, no. 1, p. 3815, 2018.

[101] A. Kalaiarasi, R. Sankar, C. Anusha et al., "Copper oxide nanoparticles induce anticancer activity in A549 lung cancer cells by inhibition of histone deacetylase," Biotechnology Letters, vol. 40, no. 2, pp. 249-256, 2018.

[102] P. Parashar, M. Rathor, M. Dwivedi, and S. Saraf, "Hyaluronic acid decorated naringenin nanoparticles: appraisal of chemopreventive and curative potential for lung cancer," Pharmaceutics, vol. 10, no. 1, p. 33, 2018.

[103] S. Vandghanooni, M. Eskandani, J. Barar, and Y. Omidi, "AS1411 aptamer-decorated cisplatin-loaded poly(lactic-coglycolic acid) nanoparticles for targeted therapy of miR-21inhibited ovarian cancer cells," Nanomedicine, vol. 13, no. 21, pp. 2729-2758, 2018.

[104] N. Amreddy, A. Babu, J. Panneerselvam et al., "Chemo-biologic combinatorial drug delivery using folate receptortargeted dendrimer nanoparticles for lung cancer treatment," Nanomedicine, vol. 14, no. 2, pp. 373-384, 2018.

[105] M. Perepelyuk, K. Sacko, K. Thangavel, and S. A. Shoyele, "Evaluation of MUC1-aptamer functionalized hybrid nanoparticles for targeted delivery of miRNA-29b to nonsmall cell lung cancer," Molecular Pharmaceutics, vol. 15, no. 3, pp. 985-993, 2018.

[106] H. M. Abdelaziz, M. Gaber, M. M. Abd-Elwakil et al., "Inhalable particulate drug delivery systems for lung cancer therapy: nanoparticles, microparticles, nanocomposites and nanoaggregates," Journal of Controlled Release, vol. 269, pp. 374-392, 2018.

[107] Z. Zhang, W. Cheng, Y. Pan, and L. Jia, "An Anticancer agent-loaded PLGA nanomedicine with glutathioneresponse and targeted delivery for the treatment of lung cancer," Journal of Materials Chemistry B, vol. 8, no. 4, pp. 655665, 2020. 
[108] F. Bénard, A. N. Barkun, M. Martel, and D. von Renteln, "Systematic review of colorectal cancer screening guidelines for average-risk adults: summarizing the current global recommendations," World Journal of Gastroenterology, vol. 24, no. 1, pp. 124-138, 2018.

[109] H. Jiang, X. Shi, X. Yu, X. He, Y. An, and H. Lu, "Hyaluronidase enzyme-responsive targeted nanoparticles for effective delivery of 5-fluorouracil in colon cancer," Pharmaceutical Research, vol. 35, no. 4, p. 73, 2018.

[110] Y. Q. Lin, J. Zhang, S. J. Liu, and H. Ye, "Doxorubicin loaded silica nanoparticles with dual modification as a tumortargeted drug delivery system for colon cancer therapy," Journal of Nanoscience and Nanotechnology, vol. 18, no. 4, pp. 2330-2336, 2018.

[111] E. Alkhader, C. J. Roberts, R. Rosli et al., "Pharmacokinetic and anti-colon cancer properties of curcumin-containing chitosan-pectinate composite nanoparticles," Journal of Biomaterials Science. Polymer Edition, vol. 29, no. 18, pp. 2281-2298, 2018.

[112] Sauraj, S. U. Kumar, V. Kumar, R. Priyadarshi, P. Gopinath, and Y. S. Negi, "pH-responsive prodrug nanoparticles based on xylan-curcumin conjugate for the efficient delivery of curcumin in cancer therapy," Carbohydrate Polymers, vol. 188, pp. 252-259, 2018.

[113] B. Kumar, R. Priyadarshi, F. Deeba et al., "Redox responsive xylan-SS-curcumin prodrug nanoparticles for dual drug delivery in cancer therapy," Materials Science and Engineering: $C$, vol. 107, p. 110356, 2020.

[114] S. U. Kumar, P. Gopinath, and Y. S. Negi, "Synthesis and bioevaluation of xylan-5-fluorouracil-1-acetic acid conjugates as prodrugs for colon cancer treatment," Carbohydrate Polymers, vol. 157, pp. 1442-1450, 2017.

[115] V. Kumar, B. Kumar, F. Deeba et al., "Lipophilic 5fluorouracil prodrug encapsulated xylan-stearic acid conjugates nanoparticles for colon cancer therapy," International Journal of Biological Macromolecules, vol. 128, pp. 204-213, 2019.

[116] K. AbouAitah, H. A. Hassan, A. Swiderska-Sroda et al., "Targeted nano-drug delivery of colchicine against colon cancer cells by means of mesoporous silica nanoparticles," Cancers, vol. 12, no. 1, p. 144, 2020.

[117] P. Wu, Q. Zhou, H. Zhu, Y. Zhuang, and J. Bao, "Enhanced antitumor efficacy in colon cancer using EGF functionalized PLGA nanoparticles loaded with 5-fluorouracil and perfluorocarbon," BMC Cancer, vol. 20, no. 1, p. 354, 2020.

[118] E. S. Al-Sheddi, N. N. Farshori, M. M. Al-Oqail et al., "Anticancer potential of green synthesized silver nanoparticles using extract of Nepeta deflersiana against human cervical cancer cells (HeLA)," Bioinorganic Chemistry and Applications, vol. 2018, Article ID 9390784, 12 pages, 2018.

[119] S. Boondireke, M. Léonard, A. Durand, and B. T. Wongsatayanon, "Encapsulation of monomyristin into polymeric nanoparticles improved its in vitro antiproliferative activity against cervical cancer cells," Colloids and Surfaces. B, Biointerfaces, vol. 176, pp. 9-17, 2019.

[120] C. Cheng, Y. Meng, Z. Zhang, Y. Li, and Q. Zhang, "Tumoral acidic $\mathrm{pH}$-responsive cis-diaminodichloroplatinumincorporated Cy5.5-PEG- g-A-HA nanoparticles for targeting delivery of CDDP against cervical cancer," ACS Applied Materials \& Interfaces, vol. 10, no. 32, pp. 26882-26892, 2018.
[121] J. Wang, “Combination treatment of cervical cancer using folate-decorated, $\mathrm{pH}$-sensitive, carboplatin and paclitaxel co-loaded lipid-polymer hybrid Nanoparticles," Drug Design, Development and Therapy, vol. Volume 14, pp. 823-832, 2020.

[122] J. Xing, Y. Cai, Y. Wang, H. Zheng, and Y. Liu, "Synthesis of polymer assembled mesoporous $\mathrm{CaCO}_{3}$ nanoparticles for molecular targeting and $\mathrm{pH}$-responsive controlled drug release," Advances in Polymer Technology, vol. 2020, 8 pages, 2020.

[123] C. Xu, W. Liu, Y. Hu, W. Li, and W. Di, "Bioinspired tumorhoming nanoplatform for co-delivery of paclitaxel and siRNA-E7 to HPV-related cervical malignancies for synergistic therapy," Theranostics, vol. 10, no. 7, pp. 3325-3339, 2020.

[124] Y. Qin, K. Chen, W. Gu et al., "Small size fullerenol nanoparticles suppress lung metastasis of breast cancer cell by disrupting actin dynamics," Journal of Nanobiotechnology, vol. 16, no. 1, p. 54, 2018.

[125] N. Kong, M. Deng, X.-N. Sun, Y.-D. Chen, and X.-B. Sui, "Polydopamine-functionalized CA-(PCL-ran-PLA) nanoparticles for target delivery of docetaxel and chemophotothermal therapy of breast cancer," Frontiers in Pharmacology, vol. 9, p. 125, 2018.

[126] V. Shafiei-Irannejad, N. Samadi, B. Yousefi, R. Salehi, K. Velaei, and N. Zarghami, "Metformin enhances doxorubicin sensitivity via inhibition of doxorubicin efflux in P-gpoverexpressing MCF-7 cells," Chemical Biology \& Drug Design, vol. 91, no. 1, pp. 269-276, 2018.

[127] V. Shafiei-Irannejad, N. Samadi, R. Salehi et al., "Reversion of multidrug resistance by co-encapsulation of doxorubicin and metformin in Poly(lactide-co-glycolide)-d- $\alpha$-tocopheryl polyethylene glycol 1000 succinate nanoparticles," Pharmaceutical Research, vol. 35, no. 6, p. 119, 2018.

[128] Z. Tian, X. Yao, and Y. Zhu, "Simple synthesis of multifunctional zeolitic imidazolate frameworks-8/graphene oxide nanocrystals with controlled drug release and photothermal effect," Microporous and Mesoporous Materials, vol. 237, pp. 160-167, 2017.

[129] W.-H. Chen, X. Yu, W.-C. Liao et al., "Drug delivery: ATPresponsive aptamer-based metal-organic framework nanoparticles (NMOFs) for the controlled release of loads and drugs (Adv. Funct. Mater. 37/2017)," Advanced Functional Materials, vol. 27, no. 37, 2017.

[130] W.-H. Chen, X. Yu, A. Cecconello, Y. S. Sohn, R. Nechushtai, and I. Willner, "Stimuli-responsive nucleic acidfunctionalized metal-organic framework nanoparticles using $\mathrm{pH}$ - and metal-ion-dependent DNAzymes as locks," Chemical Science, vol. 8, no. 8, pp. 5769-5780, 2017.

[131] P. S. O. Ozgen, S. Atasoy, B. Z. Kurt, Z. Durmus, G. Yigit, and A. Dag, "Glycopolymer decorated multiwalled carbon nanotubes for dual targeted breast cancer therapy," Journal of Materials Chemistry B, vol. 8, no. 15, pp. 3123-3137, 2020.

[132] R. Agabeigi, S. H. Rasta, M. Rahmati-Yamchi, R. Salehi, and E. Alizadeh, "Novel chemo-photothermal therapy in breast cancer using methotrexate-loaded folic acid conjugated $\mathrm{Au} @ \mathrm{SiO} 2$ Nanoparticles," Nanoscale Research Letters, vol. 15, p. 62, 2020.

[133] S.-H. Chen, T.-I. Liu, C.-L. Chuang, H.-H. Chen, W.-H. Chiang, and H.-C. Chiu, "Alendronate/folic acid-decorated polymeric nanoparticles for hierarchically targetable chemotherapy against bone metastatic breast cancer," Journal of Materials Chemistry B, vol. 8, no. 17, pp. 3789-3800, 2020. 